\title{
Pasado y presente del mundo agro-rural formoseño: un campo de estudios en conformación
}

\section{Past and present of the agro-rural world of Formosa: a field of studies in conformation}

REVISIÓN BIBLIOGRÁFICA

\section{Darío Agustín Machuca}

Universidad Nacional de Formosa, Argentina. Contacto: dariomachuca25@gmail.com

Recibido: agosto de 2021

Aceptado: octubre de 2021

\section{Resumen}

Este trabajo aborda la construcción del campo de estudios sociales agro-rurales en Formosa a partir la publicación de una serie de libros referentes a la temática en el último lustro. Así también, son mencionadas las principales líneas de investigación de este despliegue, así como sus vacancias temáticas y posibles desarrollos a futuro.Su objeto por antonomasia es el campesinado, sin embargo, la agencia estatal y las producciones capitalizadas también reciben una atención considerable. Con todo, las múltiples facetas de la dinámica entre capitalismo y campesinado constituyen el denominador común en tanto telón de fondo de las problemáticas abordadas por este desenvolvimiento académico.

Palabras clave: Formosa, ruralidad, agricultura, campesinado.

\section{Abstract}

This article is dedicated to the construction of the field of agro-rural social studies in Formosa from the publication of a series of books on the subject in the last five years. Likewise, the main research lines of this deployment are mentioned, as well as its thematic vacancies and possible future developments. Its main object is the peasantry, however, the state agency and capitalized productions also receive considerable attention. Furthermore, the multiple facets of the dynamics between capitalism and the peasantry constitute the common denominator as a backdrop to the problems studied by this academic development. 
Keywords: Formosa, rurality, agriculture, peasantry.

\section{Introducción}

En los últimos años la producción académica atinente al agro y la ruralidad formoseñas ha logrado un significativo despliegue. Es considerable la existencia tanto de trabajos de tesis (Sapkus, 2003, entre otros), capítulos de libros (Giuliano, 2021, entre otros), artículos (GirbalBlacha, 2013b; entre otros) y ponencias (Kazmer, Guillen y Sapkus, 2010, entre otros), como de obras que se interesan parcialmente en la cuestión dentro de una temáticamacro(Prieto, 2015; Giuliano, 2015). También ostenta relevancia la atención a problemáticas agro-rurales formoseñas dentro de marcosgeográficos mayores (Moyano Walker, 2020; Sapkus, Vázquez y Telesca, 2021, entre otros).Sin embargo, la proliferación de libros que tengan al agro estrictamente provincianocomo protagonista constituye una novedad que toma particular relevancia al tener en cuenta que, llamativamente, este desarrollo tiene lugar "en tiempos de papers".

Ya en 1998 Roger Chartier (2000) daba cuenta del temor que el libro electrónico suscitaba en la producción tradicional de libros impresos y, sobre todo, en sus editores. En este sentido, destaca el congreso de la Unión Internacional de Editores, realizada en Barcelona en abril de 1996. Si bien la antinomia papel vs. pantalla en su relación con la esencia del libro continúa siendo objeto de debate más de dos décadas después, las posibilidades de difusión brindadas por la web se han erigido como un importante punto a favor de los medios electrónicos y, principalmente, de los investigadores e investigadoras que buscan dar a conocer sus producciones.

Es cierto que el predominio electrónico en detrimento del papel admite resistencias en el mundo del libro. Ahora bien, en el campo de las publicaciones periódicas, el formato digital ostenta una hegemonía cada vez mayor. Elementos como el acceso abierto y la velocidad de difusión, entre otros, apuntalan esta cuestión. No solo "las revistas electrónicas se están imponiendo como sistema de transmisión de la investigacióncientífica" (Martín González y Merlo Vega, 2003, p. 155), sino que los artículos, en sí, interpelan el otrora indiscutible protagonismo de los libros -en el formato que sea- en las listas de referencias bibliográficas.

El incremento de la producción académica referente al agro formoseño da cuenta del proceso de conformación de un campo de estudios en particular. Entendemos a este como un sistema de relaciones articulado por la investigación de una temática particular en el cual se tejen redes que desarrollan el capital social de los actores en cuestión a partir de lecturas mutuas, intercambios, sistemas de evaluación por pares, realización de actividades y publicaciones conjuntas, entre otros. 
Ahora bien, artículo y libro no solo no son incompatibles, sino que son más bien complementarios. Sin embargo de ello, consideramos que el hecho de que la proliferación de obras atientes a la ruralidad formoseña, paradójicamente, tenga lugar en tiempos de papers, otorga una mayor relevancia a la cuestión en torno al desarrollo del campo de estudios.

El objetivo deeste trabajo es el análisis de los tópicos comunes que pueden señalarse en la construcción de un campo de estudios sociales agrarios en Formosa. Para ello, estudiamos la producciónde libros referentes a la temática en el último lustro. ${ }^{1}$ Con todo, dividimos nuestra exposición a partir de cuatro ejes, a saber: la reproducción social campesina y sus dificultades, la organización social para enfrentar estas adversidades, la agencia estatal como articuladora de los procesos socioeconómicos en cuestión y, por último, las producciones capitalizadas y las propuestas en torno a una "nueva ruralidad" en la provincia.

De esta manera, se espera dar cuenta de los pilares temáticos de un campo de estudios en conformación, pero también exponer posibles líneas de investigación a futuro. Con todo, consideramosa la producción bibliográfica referente a la temáticacomo un signo del desarrollo del área, y a las redes académicas como un elemento menester para la continuidad de este proceso.

\section{Entre la reproducción y la subsunción.}

Tal vez debido a la reciente conformación del campo de estudios o a las problemáticas propias de la región, el clásico debate sobre la existencia o no del campesinado no tuvo mayor raigambre en Formosa. Algo similar sucede con la disputa entre leninistas -o descampesinistasy chayanovianos -o campesinistas-, las vicisitudes acerca del futuro de este sector social. Estas últimas, sin embargo, parecieran encontrar un terreno un tanto más fértil en estas latitudes.

Dadas las características estructurales del campesinado formoseño, más cercanas a la proletarización y la desagrarización que a la capitalización, gran parte de la producción académica en cuestióngira en torno a la constricción de la reproducción minifundista. En ellos, el capitalismo, con el Estado como su herramienta predilecta,se erige en antítesis del campesinado. En este sentido, podemos afirmar que los procesos de subsunción (Whatmore et al, 1987, p. 27, citados por Rofman, García, García, Lampreabe, Rodríguez y Vázquez Blanco, 2008, p. 101) son un pilar del campo de estudios.

\footnotetext{
1 Si bien nos centramos en la publicación de libros, por momentos también nos remitiremos a otros formatos de producción académica a fin de cubrir el mayor espectro posible de temáticas investigadas en relación al agro formoseño.
} 
En el plano historiográfico, destacan los aportes de Vázquez (2020) en torno al campesinado de los años sesenta. ${ }^{2}$ El autor señala problemáticas comoel monocultivo algodonero,su gran vulnerabilidad ante la crisis de los cultivos regionales, y la carencia de tierras en propiedad. A estos elementos productivos, agrega otros como el componente inmigrante limítrofe, la carencia de derechos políticos en plenitud debidotanto a las características institucionales de Formosa como al contexto político nacional, el analfabetismo y, sobre todo, la ausencia de canales de expresiónpropios o entidades representativas del sector.

En cierta medida, varios de estos problemas continuaron hasta el siglo XXI. Las trasformaciones socio-productivas desplegaron procesos de desagrarización, des-ruralización, descampesinización, proletarización agraria y ganaderización que restringen las posibilidades de reproducción minifundista. ${ }^{3}$ Aún en nuestros días, como plantea Sapkus (2021), en Formosa "lo rural sigue estando asociado, más allá del tenue crecimiento de la infraestructura, a la pobreza y a escasas posibilidades de ensanchamiento del abanico vital de vida". Esto es visible en descripciones como las de Ayala (2016), ${ }^{4}$ quien en sus investigaciones en torno a los usos de los bosques nativos en la provincia menciona comúnmente viviendas de madera en las comunidades rurales.

Ante las condiciones estructurales de pobreza rural y el estrangulamiento a la pequeña producción agrícola, el campoformoseño vio el surgimiento de nuevas estrategias de reproducción de los sectores minifundistas. Muracciole (2019) plantea una diversificación de la pequeña producción a partir de los años noventa con la horticultura como principal actividad. ${ }^{5}$ En sintonía, Ayala (2016) da cuenta de cómo varios de sus entrevistados son productores hortícolas que comercializan su producción en ferias francas. En ambos casos, las unidades agrícolas en cuestión por lo general no superan las 15 ha.Así también, ambos autores destacan

${ }^{2}$ El título del libro de Cristian Vázquez, fruto de las investigaciones realizadas en el marco de su tesis de maestría en Ciencias Sociales, es Campesinos de pie: la formación del movimiento campesino en Formosa. La obra espublicada de manera conjunta por la Universidad Nacional de La Plata, la Universidad Nacional de Misiones y la Universidad Nacional de General Sarmiento como parte de la colección Entre los libros de la buena memoria. Vázquez forma parte del Instituto de Investigaciones sobre Lenguaje, Sociedad y Territorio (INILSyT) de la Universidad Nacional de Formosa (UNaF).

${ }^{3} \mathrm{Si}$ bien estas problemáticas no hay sido específicamente abordadas es estos términos en los libros aquí estudiados, sí encuentran un importante asidero en otros formatos a partir de las producciones elaboradas por Sapkus y sus colaboradores.

${ }^{4}$ El libro de Miryan Ayala, Desarrollo Rural y Extensión Forestal: bosques nativos, colonias rurales y representaciones sociales en la provincia de Formosa, publicado por La Colmena, corresponde a la tesis doctoral en Estudios Sociales Agrarios de su autora. Ayala es docente investigadora de la Facultad de Recursos Naturales (FRN) de la UNaF.

5La obra de FedericoMuracciole, publicada por Edunaf y titulada "Nos arreglábamos con la producción": políticas sociales en familias campesinas del sur formoseño, forma parte de las investigaciones realizadas por el autor en el marco de su tesis doctoral en Estudios Sociales Agrarios. Muracciole, también se desempeña en la UNaF, más precisamente en las facultades de Administración, Economía y Negocios (FAEN) y Ciencias de la Salud (FCS). 
la pluriactividad como fenómeno del nuevo siglo. El primeroda cuenta de la creciente importancia del empleo asalariado e integra a actividades como la producción ladrillera dentro de la diversificación del campo formoseño. La segunda, por su parte, menciona repetidas veces trabajos de changarín, motosierrista, albañilería y empleos en el sector terciario de ciudades cercanas a las comunidades estudiadas.

En el campo formoseño, las transformaciones socio-productivas de los últimos años no sólo dan lugar a desagrarizaciones en su forma pura, sino también a la combinación entre ingresos prediales y extra-predialesfacilitados en cierta medida por la estacionalidad del ciclo de producción agrícola que, autores como Boltvinik (2012),continúan señalando como causa principal la pobreza campesina en el contexto de formaciones sociales capitalistas.

Otro elemento importante que empezó a ser analizado con el desarrollo del campo de estudios en Formosa corresponde a la influencia de los programas de transferencia formales de ingresos -también denominados "planes de asistencia social- dentro delas estrategias dereproducción de las familias campesinas. Es Muracciole (2019) quien plantea esta línea de investigación y, si bien reconoce a los ingresos provenientes de la Asignación Universal por Hijo $(\mathrm{AUH})$ y el programa Progresar como claves en términos netamente económicos, también destaca su preponderancia en el plano educativo a partir de los requisitos para el acceso a sus beneficios.

Un capítulo aparte en el entrecruzamiento entre la subsunción y la reproducción refiere a lo que Lapegna (2019) denomina como "adaptación". ${ }^{6}$ El autor tensiona la noción de un campesinado portavoz del "ecologismo de los pobres" (Martinez-Alier, 2002) estudiando la adopción del algodón transgénico promovido por el gobierno provincial en Formosa. No solo plantea que el agronegocio marginaliza al campesinado y que este resiste tales fuerzas. Sino que tambiénse dedica a la "adaptación" productivade este sector ante un nuevo contexto agrario. En palabras de una de sus entrevistadas: "[los productores de soja] nos están acostumbrando a lo de ellos" (Lapegna, 2019, p. 214). ${ }^{7}$

Si bien Formosa presenta un terreno sumamente fértil para los estudios que se aproximen a la muerte del campesinado, también invita a preguntarnos acercade posibles transformaciones de este sector social. Un campesino inmigrante, algodonero y ocupante informal de tierras en

\footnotetext{
6 El libro de Pablo Lapegna, correspondiente a una versión revisada de su tesis doctoral en Sociología, tiene como título La Argentina transgénica: de la resistencia a la adaptación, una etnografía de las poblaciones campesinas. La obra es publicada por Siglo XXI, y su autor desarrolla sus actividades en el Departamento de Sociología y en el Instituto de Estudios de América Latina y el Caribe de la Universidad de Georgia.

${ }^{7}$ Lapegna (2019) aborda la adopción de este algodón transgénico como parte de la "desmovilización" de la protesta campesina contra el modelo agrotóxico sojero. La promoción gubernamental del regreso -o sostenimiento- del otrora "rey blanco" a los campos formoseños merece ser estudiada en mayor profundidad.
} 
los años sesenta presenta una considerable distancia de un campesino que también atiende un quiosco y tiene a la AUH entre sus principales ingresos ¿Qué es el campesinado -en Formosa en el siglo XXI- y qué no lo es? Este es un interrogante que Sapkus (2021) plantea proponiendo al campesinado actual como la variable rural de las "clases de trabajo" de Henry Bernstein, un estrato que si bien puede ostentar cierto acceso a determinados medios de producción no cuenta con la capacidad de reproducirse a sí mismo de forma autónoma. Ciertamente, este nuevo contexto histórico donde la subsunción y la reproducción interactúan constantemente en un espacio fronterizo y de periferia rezagadaplantea un sinfín de nuevas preguntas para este campo de estudios en conformación.

\section{La organización social.}

Si el avance del capitalismo en la agricultura ha restringido la reproducción de la pequeña producción mercantil, el campesinado también se ha organizado para, de modo u otro, interpelar las múltiples realidades que surgen de esta relación. En el caso formoseño, los estudios sobre las luchas sociales del mundo rural giran en torno a la Unión de Ligas Campesinas de Formosa (ULICAF) de los años setenta y el Movimiento Campesino de Formosa (MOCAFOR) de la actualidad.

Con respecto al primer caso, Vázquez (2020) estudia la conformación de la organización rural durante los años sesenta a partir de tres ejes. El primero corresponde a las condiciones de vida de un campesinado inmigrante y sin tierras que se agravaron con la crisis algodonera y el proceso de privatización de tierras fiscales iniciado durante la autodenominada "Revolución Argentina" (1966-1973). El segundo eje corresponde a una acción estatal, la extensión rural del Instituto Nacional de Tecnología Agropecuaria (INTA) dedicada a mujeres, adolescentes y jóvenes como espacio de formación y sociabilidad. Por otro lado, el tercer eje gira en torno a la acción eclesial de las Hermanas Misioneras Cruzadas de la Iglesia primero, y del Movimiento Rural de Acción Católica (MRAC) después.

Las demandas del campesinado y su proceso organizativo dieron lugar al nacimiento de la ULICAF como un órgano propio del sector en 1971 que, sin embargo, contaba aún con el apoyo del obispado.Retomando aportes de autores como Sidney Tarrow, Daldovo (2018) sostiene que este constituyó un movimiento social, y se ocupa de su derrotero mediante una división de la experiencia en cuatro etapas. ${ }^{8}$ La primera de ellas corresponde al funcionamiento

\footnotetext{
${ }^{8}$ El título del libro de Mónica Daldovo, fruto de las investigaciones realizadas en el marco de su tesis de doctorado en Ciencias Sociales, es Campesinado, Iglesia católica y Estado en Formosa: el caso de la ULICAF (años 1970), publicada Prohistoria. La autora es docente investigadora de la Facultad de Humanidades (FH) de la Universidad Nacional de Formosa (UNaF).
} 
del MRAC en la provincia y la conformación de la ULICAF. La segunda etapa refiere a esta organización hasta la asunción del gobernador justicialista Antenor Gauna en mayo de 1973. Entrences, inicia el período de auge y mayor efervescencia liguista, truncado con la intervención federal a la provincia en noviembre de ese mismo año. En ese momento, se despliega el proceso de desarticulación del movimiento campesino con la promoción de otras organizaciones y la persecución de sus militantes, estrategia agudizada luego del asalto al Regimiento de Infantería Monte 29 el 5 de octubre de 1975, primero, y el golpe del 24 de marzo de 1976, después. ${ }^{9}$

Desde entonces no han sido pocas las voces que pretendieron alzarse como herederas de la ULICAF. Sin dudas, las más disruptivas de ellas, nacen desde el MOCAFOR, movimiento estudiado por Lapegna (2019). Este autor, presenta su análisis a partir de dos grandes anclajes: los cultivos transgénicos y los procesos de desmovilización.

EI MOCAFOR surge a fines de los años noventacomo unión de un grupo de militantes del Movimiento Agrario de Formosa (MAF) disconformes con su subordinación al gobierno provincial, un comité campesino de base creado por monjas y un grupo de mujeres (Sapkus, 2002, citado en Lapegna, 2019, p. 113). Formosa no escapó al avance del agronegociode la soja transgénica durante la última década del siglo XX. Así, en 2003 un caso de deriva agroquímicadañó la salud de los campesinos y campesinas de las comunidades de Monte Azul y Moreno, destruyó sus cultivos y mató a sus animales. Una intensa movilización desplegada a través del MOCAFOR denunció a la empresa sojera e interpeló al gobierno provincial.

En 2009, sucedió algo similar, sin embargo, apenas se hicieron apelaciones a través de canales institucionales. Para Lapegna (2019) esto significa un proceso de desmovilización ocasionado en gran parte por el reconocimiento institucional logrado por el MOCAFOR ante instancias estatales nacionales que provocó una "presión 'desde arriba"' que la organización debió consensuar con la "presión 'desde abajo'” de las demandas de sus bases.

A pesar de ello -y de fenómenos como la "adaptación" y las prácticas relacionadas al clientelismo también estudiadas por el autor-, el discurso de la organización continúa interpelando tanto al gobierno provincial como a la agroindustria o, mejor dicho, a sus consecuencias sociales y ambientales. De esta manera, el juego entre la reproducción y la subsunción encuentra una arista en la organización social campesina de Formosa, y en la dinámica entre esta y los entramados estatales en sus distintas escalas.

En otro libro (Daldovo, 2021),agrega una comparación entre los procesos liguistas formoseño y paraguayo.

${ }_{9}$ Un sector interesante que Daldovo(2018) menciona pero al cual no se dedica en profundidad, es el de los medianos productores agrupados con el incentivo de la Sociedad Rural bajo el signo de DEPROA (Defensa del Productor Agropecuario). Esta entidad representa un elemento pasible de ser analizado con mayor detenimiento. 
De este modo, la organización social como respuesta a los procesos de estrangulamiento a la reproducción de la vida campesina presenta un considerable despliegue en la conformación del campo de estudios sociales agro-rurales de Formosa. Sin embargo, aun recurriendo a otras formas de producción académica, observamos ciertos desbalances en términos temporales diacrónicos. En este sentido, la experiencia liguista y la resistencia al proceso neoliberalizador de los años noventa son mucho más atendidas que las agencias desarrolladas durante las últimas dictadura y post-dictadura. Así también, los estrechos vínculos del Movimiento Agrario de Formosa (MAF) con la estructura de gobierno provincial, si bien son mencionados por Lapegna (2019), aún presentan múltiples aristas a ser estudiadas.

\section{El rol del Estado.}

El papel del estado en los procesos socio-territoriales de Formosa es una de las aristas que mayor interés despierta en el campo de estudios. Así, por ejemplo, el proceso de privatización y concentración de tierras que tuvo lugar en la provincia durante la "Revolución Argentina" es una de las problemáticas más abordadas por los trabajos historiográficos, en su mayoría deudores de los pioneros aportes de Daniel Slutzky y Víctor Brodersohn.

Durante el gobierno de facto de Onganía, se intentó integrar a zonas productivas marginales al circuito productivo nacional revalorizando la cría de ganado en la región chaqueña por medio de medianos y grandes productores beneficiados por la política de tierras y los incentivos para el mejoramiento de sus rodeos (Beck, 2007, énfasis p. 3). Este proceso promovido por el Estado constituye la causa principal de la reacción campesina que comentamos más arriba. Sin embargo y como apuntamos anteriormente, es Vázquez (2020) quien introduce una nueva arista a partir del análisis de los mecanismos de extensión rural con adolescentes, jóvenes y mujeres desplegados por un organismo público como el Instituto Nacional de Tecnología Agropecuaria (INTA) y las particularidades que estosadquirieron en el caso formoseño. Los Clubes 4-A (para jóvenes y adolescentes) y los Hogares Rurales (para

mujeres) acabaron constituyendo importantes espacios de capacitación, reflexión y socialización de los campesinos y campesinas de la zona en torno a los problemas que les aquejaban. De esta manera, el autor muestra una interesante paradoja: mientras las políticas desarrollistas despojaban al campesinado, la realidad "en terreno" de las actividades de una institución estatal fue una de las bases del posterior despliegue del MRAC en la zona, que cuestionó fuertemente a la estructura agraria vigente.

Daldovo (2018) se ocupa de la relación entre la ULICAF y los distintos gobiernos locales sucedidos entre la "Revolución Argentina" y la última dictadura cívico-militar. Estos vínculos van 
desde la represión estatal al movimiento, teniendo uno de sus primeros hechos en la desarticulación de una concentración campesina en octubre de 1972, hasta el proyecto de concesión de 380 mil hectáreas que, sin embargo, requerían de grandes inversiones por parte de sus beneficiarios para poder ser explotadas. Así se abordan tanto instancias de abierta confrontación como cierta tendencia al diálogo.

En la mayor parte de las aristastratadas en este artículo se nota un énfasis del mundo académico predominante en los tiempos recientes, esto es, en la neoliberalización de fines del siglo $\mathrm{XX}$ y las trasformaciones socioproductivas de las últimas décadas. De este modo, los trabajos dedicados a la etapa territoriana de la historia formoseña y períodos como las últimas dictadura y post-dictadura presentan un menor despliegue. En este sentido, es necesario remarcar que el campo historiográfico local expone las características propias de tardíodesarrollo institucional de la provincia. A ello, se suma el carácter relativamente nuevo de los estudios sobre historias agrarias y rurales extrapampeanas (Girbal-Blacha, 2013a). Así, Vázquez (2020, p. 29) plantea que "para el caso particular de Formosa, debemos referir el exiguo desarrollo de las diferentes disciplinas de las ciencias sociales que impidió crear una agenda de investigación propia", mientras Daldovo (2018, p. 17) afirma que "en un área periférica, donde las investigaciones no han tenido aún el desarrollo observado en otros espacios del país, resulta necesaria la recuperación de la memoria colectiva".En este sentido, resultan clave la ubicación de los documentos de la etapa territorial en archivos fuera de la provincia, la destrucción de fuentes en períodos signados por la violencia institucional, y cuestiones atinentes a la archivística de la historia rural, como el analfabetismo de los actores sociales en cuestión.

En los trabajos en torno a la actualidad, se torna más nítida la presencia de distintas perspectivas en acerca del rol del Estado. En este sentido, las borrosas fronteras entre Estado y gobierno se tornan aún más tenues en una provincia caracterizada por la hegemonía electoral de una misma gestión. ${ }^{10} \mathrm{Si}$ bien en los libros que abordamos, las interpretaciones van tanto desde un Estado "para el desarrollo" hasta un Estado clientelar, existe un consenso en afirmar que el mismo juega un rol fundamental en el devenir de los procesos socio-productivos de los últimos años.

La temática ineludible al adentrarse en la acción estatal dentrodel agro formoseño actual es el Programa de Asistencia Integral para el Pequeño Productor Agropecuario (PAIPPA). ${ }^{11}$ Daldovo (2021, p. 94) sostiene como hipótesis que "el Proyecto de desarrollo territorial rural

\footnotetext{
10 Un análisis de los procesos políticos de las provincias periféricas argentinas desde el retorno a la democracia puede consultarse en Vaca Ávila (2019).

${ }^{11}$ Programa estatal iniciado en 1996 y transformado en Instituto Provincial de Acción Integral para el Pequeño Productor Agropecuario (Instituto PAIPPA) en 2004.
} 
diseñado y ejecutado desde el PAIPPA, ha recuperado y fortalecido los principios rectores de la ULICAF". 12 Para sostener este planteo, la autora se sirve de sus geografías de principal despliegue, de las trayectorias de algunos de sus representantes, y de ciertas demandas del movimiento y logros del Instituto, como la entrega de títulos de propiedad. En este sentido, expresa no sólo que "la ULICAF asumió un proyecto de desarrollo territorial para los campesinos", sino que además sus principios "han sido resignificados por el PAIPPA" (Daldovo, 2021, pp. 16; 18, destacado en el original). Lo que aquí nos interesa destacar es que, representativos de distintas épocas de la historia provincial, y conformados desde distintos sectores, ambos tienen como eje a la reproducción del campesinado.

EI PAIPPA, organismo desconcentrado dependiente directamente del Ejecutivo provincial, atiende en diferentes cuestiones a las familias productoras a las cuales denomina como "paipperos". Estas, en el caso estudiado por Daldovo (2021) -Riacho HeHe-, no llegan a las 10 ha. En tanto estrategia gubernamental, promueve la diversificación de la producción, facilita el acceso de los productores a los insumos, y estimula la siembra directa y los cultivos no tradicionales. También promociona el agrupamiento de productores y la comercialización de mercancías agrícolas en ferias; fomenta circuitos de agregado de valor, como pequeñas fábricas de almidón de mandioca, y atiendea la producción con maquinarias y asistencia técnica. Asimismo, promueve la construcción de viviendas, otorga títulos de propiedad, facilita la asistencia sanitaria e impulsa obras infraestructura local e irrigación en los campos.

Sin embargo, una temática que aun merece ser abordada con mayor profundidad corresponde al grado de impacto de estas políticas en la realidad campesina en toda la provincia. A modo de ejemplo, El Angelito, una de las colonias estudiadas por Ayala (2016, p. 115 , el destacado es nuestro) "cuenta con alrededor de cien familias de pequeños productores [...] unas pocas familias que son asistidas por el PAIPPA [...] no superan las tres hectáreas". ${ }^{13}$ Si bien la extensión de las unidades agropecuarias es solo uno de los tantos elementos a tener en cuenta al momento de analizar los procesos productivos, también es cierto que constituye uno de los principales meollos de la cuestión agraria. Con todo, a pesar de que el PAIPPA, junto a otras iniciativas estatales, morigeran los efectos de la subsunción en el campesinado local, los efectos de la transformación socioproductiva del campo formoseño continúan latentes.

Otra de las limitaciones de los programas estatales para el campo es expuesta por Ayala (2016, p. 165), quien señala "la falta de políticas de real aplicabilidad para el sector [forestal], la

\footnotetext{
12 Este libro de Mónica Daldovo, corresponde a una actualización de su tesis de maestría en Desarrollo Territorial, tiene como título Formosa: de lo frustrado a lo logrado. Pervivencia de las Ligas Campesinas en las actuales políticas agropecuarias del Estado provincial, y es publicada por Prohistoria.

${ }^{13}$ Cabe destacar, sin embargo, que a lo largo del libro Ayala menciona productores con hasta diez ha relacionados al PAIPPA.
} 
falta de técnicos y de presencia institucional en el medio para la promoción de actividades con relación al bosque nativo...". En otras palabras, la autorapropone vincular las prácticas de la extensión rural con las ciencias forestales desarrollando de este modo los mecanismos de extensión forestal.

El extractivismo forestal y el rol ausente -o permisivo- del Estado en su regulación es mencionado tanto por Ayala como por Lapegna. Si bien ambos relacionan este proceso con la expansión de la frontera sojera, es este último quien desarrolla enfáticamente la relación entre Estado y agronegocio.

Para Lapegna (2019, p. 38), Formosapresenta "un gobierno provincial autoritario que los campesinos deben soportar". El autor nota la presencia de políticas clientelares en múltiples escalas, incluso dentro de organizaciones sociales opositoras a la gestión local. Así también, da cuenta de cómo el reconocimiento del Estado nacional al MOCAFOR favoreció la continuidad de la organización, a la vez que contribuyó a su "desmovilización". En una línea similar, señala al gobierno provincial como promotor de la "adaptación" del campesinado a variables transgénicas como las del algodón.

El autor ve un Estado simpático para con la penetración del modelo sojero en la región y que, a su vez, desestima los reclamos campesinos. Un ejemplo señalado estriba en los vínculos de determinados actores, así

los terratenientes y políticos formoseños empezaron a cultivar soja en esa zona. El más importante era [...] un diputado y jefe político local, que además era un gran terrateniente [...] Otro de los principales productores de soja de la zona era el sobrino de quien en ese momento era ministro de Producción de la provincia (Lapegna, 2019, p. 121). ${ }^{14}$

Existen otros trabajos que señalan al Estado como articulador del proceso de acumulación de capital en el agro provinciano en los últimos años (Giuliano, 2021; Iñigo Carrera, 2017; Sapkus y Giuliano, 2020, entre otros). Sin embargo, no nos detuvimos en ellos por intentar centrarnos principalmente en las publicaciones en formato libro, cuyo despliegue nos interesa estudiar como ejemplo del desarrollo del campo de estudios.

En síntesis, este apartado da cuenta de la importancia que las políticas públicas agrorurales revisten como temática propia dentro del mundo académico que nos ocupa. Así, los estudios en torno a un Estado "para el desarrollo rural" dialogan con los referentes a un Estado neoliberalizador. A ello, se suma la atención prestada al PAIPPA, el programa de agencia agro-

\footnotetext{
${ }^{14} \mathrm{El}$ autor también menciona los problemasque debieron enfrentar aquellas personas vinculadas al Estado que interpelaron el discurso gubernamental (véase Lapegna, 2019, pp. 134-135; 144).
} 
rural gubernamental que ya cuenta con un cuarto de siglo de historia y se erige como el elemento más ponderado por la gestión estatal en la materia.

\section{Otras cuestiones: producciones capitalizadas y ¿la posibilidad de una "nueva ruralidad”?}

Problemáticas también abordadas en la producción bibliográfica de los últimos años refieren a producciones capitalizadas relacionadas al avance de la frontera sojera y la ganaderización del sector primario en la provincia. Así, Lapegna (2019) debate con perspectivas tecnoproductivistas promotoras del modelo transgénico a la vez que da cuenta de las transformaciones del agro formoseño. Ayala (2016, p. 180), por su parte, da cuenta de un sureste provincial donde "los productores rurales, tanto de El Esterito como de El Angelito [...] llevan a cabo prácticas productivas basadas preponderantemente en la ganadería".

Mientras Lapegna (2019) analiza las implicancias que la aplicación de agrotóxicos en la producción sojera produce en la salud de las poblaciones campesinas y sus producciones, también se dedica a mecanismos por los cuales el Estado promueve la utilización de variedades transgénicas del algodón por parte de estas desfavorecidas capas sociales. Lo que en este apartado nos compete, es que el autor nos invita a ver otra cara de los procesos socioproductivos desplegados en la provincia: la cara del alquiler de grandes extensiones y de los ciclos productivos regulados por tecnologías como avionetas, fumigadoras "mosquito" y litros de 2,4D; en otras palabras, la cara favorecida por las dinámicas de trasformación agraria contemporáneas.

El avance de la ganadería, presente en el libro de Ayala (2016), expone una realidad señalada ya en trabajos anteriores (Kazmer, Guillen y Sapkus, 2010; Guillen, Kazmer y Sapkus, 2012). Esta cuestión se encuentra fuertemente imbricada en fenómenos como la transformación del uso del suelo en favor de cultivos forrajeros, la reducción del empleo directo de fuerza de trabajo en el sector primario de la provincia y el despoblamiento de las áreas rurales.

Otro elemento presente en la producción bibliográfica responde a la posibilidad de una "nueva ruralidad" en el campo formoseño. La vinculación de áreas rurales con centros urbanos, y la fuerte presencia de actividades rurales no agropecuarias por parte de los mismos productores dando lugar a fenómenos de "pluriactividad", son cuestiones que Ayala (2016, pp. 124-131) engloba como "fenómenos de la nueva ruralidad". En esta línea, aunque sin emplear este concepto, autores como Muracciole (2019) exponen también elementos relacionados a la ampliación del sistema educativo en las áreas rurales.

Si bien existen trabajos que tensionan los postulados epistemológicos de la nueva ruralidad (ver Kay, 2009; para el caso formoseño ver Sapkus, 2021), lo cierto es que hasta el 
momento no existen propuestas que se dediquen a estudiar de manera específica al campo local en virtud de su relación o no con uno de los conceptos más disputados en el marco de los estudios rurales latinoamericanos del nuevo siglo.

Las producciones capitalizadas gozan de mayor atención en los abordajes situados cronológicamente en el nuevo siglo que en aquellos dedicados a franjas temporales pretéritas. Así, el agronegocio sojero y la ganadería son estudiadas en tanto muestras de las transformaciones socioproductivas más recientes. Empero, en el caso del mundo pecuario previo a la oleada neoliberalizadora de fines del siglo XX encontramos un terreno fértil para nuevas líneas de investigación. Algo similar ocurre con la controvertida "nueva ruralidad" y su existencia (o no) en Formosa, dado que hasta el momento no existen trabajos específicamente dedicados a la cuestión.

\section{Conclusiones}

A lo largo de este trabajo dimos cuenta de la conformación de un campo de estudios propio: el de los estudios sociales rurales y agrarios en la provincia de Formosa. En este, el objeto por antonomasia es el campesinado. Sin embargo, también se encuentran presentes la agencia estatal y las producciones capitalizadas. Con todo, las múltiples facetas de la dinámica entre capitalismo y campesinado constituyen el telón de fondo de las problemáticas abordadas.

La publicación de libros referentes a este campo de estudio -junto con producciones académicas en otros formatos- a pesar de un contexto signado por la hegemonía de los papers da cuenta un cambio en la materia. Las problemáticas de reproducción del campesinado, su organización social y la estatalidad son los principales ejes en torno a los cuales se tejen los recientes aportes. Sin embargo, aún existen terrenos sumamentefértiles a ser trabajados, algunos de los cuales se mencionaron en este trabajo. Así, por ejemplo, las relaciones entre "lo campesino" y "lo indígena", las asociaciones de medianos y grandes productores, las transformaciones socio-productivas del oeste provincial, las particularidades con base en motivos de géneros y rangos etarios, y los cambios operados durante la última dictadura cívicomilitar, entre otros, constituyen importantes aristas para la ampliación de esta propuesta.

La continuidad de esta construcción se encuentra inherentemente relacionada al desarrollo institucional de las casas de estudio y de los centros de investigación implicados. Las redes académicas y la formación de nuevas generaciones de investigadores son condimentos imprescindibles para la cuestión. Así también, políticas públicas orientadas al desarrollo científico de las denominadas Áreas de Vacancia Geográfica se erige en un elemento menester, al igual que las vinculaciones interinstitucionales y la accesibilidad a las fuentes documentales. Por lo pronto, el mundo agro-rural formoseño pide a gritos continuar siendo estudiado. 


\section{Referencias bibliográficas}

Ayala, M. (2016). Desarrollo rural y extensión forestal: Bosques nativos, colonias rurales y representaciones sociales en la provincia de Formosa. Vicente López, Argentina: La Colmena. Beck, H. (2007). Latifundios, minifundios e intrusos. Problemáticas de la tierra rural formoseña. En XVII Encuentro de Geohistoria Regional. Instituto de Investigaciones Geohistóricas, Resistencia.

Boltvinik, J. (2012). Pobreza y persistencia del campesinado. Teoría, revisión bibliográfica y debate internacional. Mundo Siglo XXI, VIII(28), 19-39.

Chartier, R. (2000). Cultura escrita, literatura e historia. México, México: Fondo de Cultura Económica.

Daldovo, M. (2018). Campesinado, Iglesia católica y Estado en Formosa. El caso de la ULICAF (años 1970). Rosario, Argentina: Prohistoria.

Daldovo, M. (2021). Formosa: de lo frustrado a lo logrado. Pervivencia de las Ligas Campesinas en las actuales políticas agropecuarias del Estado provincial. Rosario, Argentina: Prohistoria. Girbal-Blacha, N. (2013a). Historia y memoria rural. Tramas regionales para la construcción de la historia rural argentina. Breves Contribuciones del I.E.G.,(24), 118-131.

Girbal-Blacha, N. (2013b). Reclamos de una población rural postergada. Política y "justicia a la carta". Visibilidad en Formosa - Argentina (1884-1955). Revista de Historia del Derecho, (45), 73-110.

Giuliano, E. F. (2015). Sociedades periféricas y multiterritorios: Estructura social de Formosa. 1980-2002. Vicente López, Argentina: La Colmena.

Giuliano, E. F. (2021). El acoplamiento fragmentario del Estado en el Complejo Ganadero Formoseño. En C. Cowan Ross, M. Berger y A. García (Comps). Hacer Estado en el campo (pp. 31-72). San Juan, Argentina: Universidad Nacional de San Juan.

Guillen, J. L, Kazmer, J. y Sapkus, S. (2012). Desarrollo y agro en la provincia de Formosa en el cambio de siglo. En XXXII Encuentro de Geohistoria Regional. Instituto de Investigaciones Geohistóricas- Universidad Nacional del Nordeste.

Iñigo Carrera, V. (2017). Frontera agropecuaria y territorio en el noreste de argentina: su avance y ordenamiento en la provincia de Formosa. Revista GeoPantanal, (22), 55-72.

Kay, C. (2009). Estudios rurales en América Latina en el periodo de globalización neoliberal: ¿una nueva ruralidad?.Revista Mexicana de Sociología, 71(4), 607-645.

Kazmer, J; Guillen, J. L. y Sapkus, S. (2010). El agro en la provincia de Formosa en las últimas décadas. En XXX Encuentro de Geohistoria Regional. Instituto de Investigaciones Geohistóricas-Universidad Nacional del Nordeste, Resistencia. 
Lapegna, P. (2019). La Argentina transgénica: de la resistencia a la adaptación, una etnografía de las poblaciones campesinas. Buenos Aires, Argentina: Siglo XXI.

Martín González, J. C. y J. A. Merlo Vega. (2003). Las revistas electrónicas: características, fuentes de información y medios de acceso. Anales de documentación, (6), 155-186.

Martinez-Alier, J. (2002). The Environmentalism of the Poor. Johannesburg, South Africa: United Nations Research Institute for Social Development (UNRISD)/University of Witwatersrand.

Moyano Walker, M. (2020). El mundo rural en emergencia. Las Ligas Agrarias del NEA. Buenos Aires, Argentina: Teseo Press.

Muracciole, F. (2019). "Nos arreglábamos con la producción": Políticas sociales campesinas en el sur formoseño. Formosa, Argentina: Edunaf.

Prieto, A. (2015). Para comprender a Formosa: Una aproximación a la historia provincial 18791976. Buenos Aires, Argentina: Dunken.

Rofman, A.; García, A.; García, L.; Lampreabe, F.; Rodríguez, E. y Vázquez Blanco, J. M. (2008). Subordinación productiva en las economías regionales de la posconvertibilidad. Realidad económica, (240), 97-132.

Sapkus, S. (2003). Campesinado y protesta rural en el Nordeste argentino. El movimiento campesino de Formosa (1995-2000) (Tesis de maestría). Posadas, Argentina: Universidad Nacional de Misiones.

Sapkus, S. (2021). Ruralidad, campesinado y neoliberalización: indagando la Formosa del siglo XXI. En Sapkus, S.; Vázquez, C. y Telesca, I. Ruralidad y sujetos subalternos: Una mirada comparada al nordeste argentino (pp. 55-82). Formosa, Argentina: Edunaf.

Sapkus, S. y Giuliano, E. F. (2020). El circuito algodonero-textil en Formosa, Argentina 20032015. Apuntes del CENES, 39(70), 209-232.

Sapkus, S.; Vázquez, C. y Telesca, I. (comps). (2021). Ruralidad y sujetos subalternos: Una mirada comparada al nordeste argentino. Formosa, Argentina: Edunaf.

Vaca Ávila, P. (2019). Predominio y alternancia en provincias periféricas (Argentina 1983-2015) (Tesis doctoral). Buenos Aires, Argentina: Universidad Nacional de San Martín.

Vázquez, C. (2020a). Campesinos de pie: La formación del movimiento campesino en Formosa. Los Polvorines/La Plata/Posadas, Argentina: Universidad Nacional de General Sarmiento/Universidad Nacional de La Plata, Facultad de Humanidades y Ciencias de la Educación/Universidad Nacional de Misiones. 